\title{
Những nhà khoa học xuất sắc thì cần được đầu tư mạnh mẽ hơn
}

\author{
Thùy Linh
}

Giáo dục Việt Nam

February 18, $2021(06: 10)$

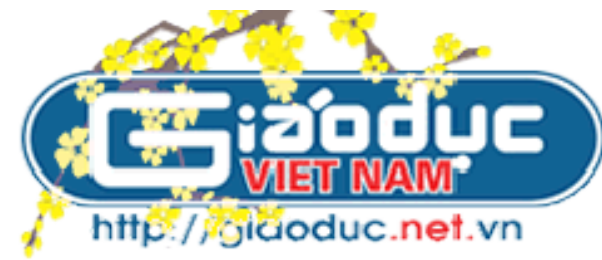

https://giaoduc.net.vn/giao-duc-24h/nhung-nha-khoa-hoc-xuat-sac-thi-can-duoc-dautu-manh-me-hon-post215476.gd 


\section{Nhũng nhà khoa học xuất sắc thì cần được đầu tư mạnh mẽ hơn - Giáo dục Việt Nam}

Tạp chí điện tử Giáo dục Việt Nam có cuộc trao đổi với Tiến sĩ Phạm Hiệp- Giám đốc nghiên cứu, Trung tâm Nghiên cứu và Phát triển giáo dục Edlab Asia, một chuyên gia về giáo dục đại học những nhìn nhận và kỳ vọng về vấn đề phát triển khoa học công nghệ nước nhà.

Tiến sĩ Hiệp đánh giá, nghiên cứu khoa học của Việt Nam đã có những bước chuyển mình tích cực, căn bản trong 5 năm năm qua. Theo báo cáo mới xuất bản gần đây của ISI cho thấy trong các nước Đông Nam Á và Nam Á thì Việt Nam có tốc độ tăng trưởng về công bố quốc tế nhanh nhât, vói tốc độ tăng trưởng trung bình khoảng $14 \%$ trong hơn 30 năm qua.

Điều này xuất phát từ các chính sách vĩ mô của nhà nước bao gồm 2 Bộ (Bộ Giáo dục và Đào tạo; Bộ Khoa học công nghệ) cũng như những phản ứng kịp thời của các co sở giáo dục đại học.

"Bên cạnh đó cũng không thể không kể đến là lực lượng nhà khoa học nghiên cứu trẻ được đào tạo, học hành bài bản ở nước ngoài đã trở về và làm việc, sinh hoạt nghiên cứu khoa học trong nước", chuyên gia Phạm Hiệp thừa nhận.

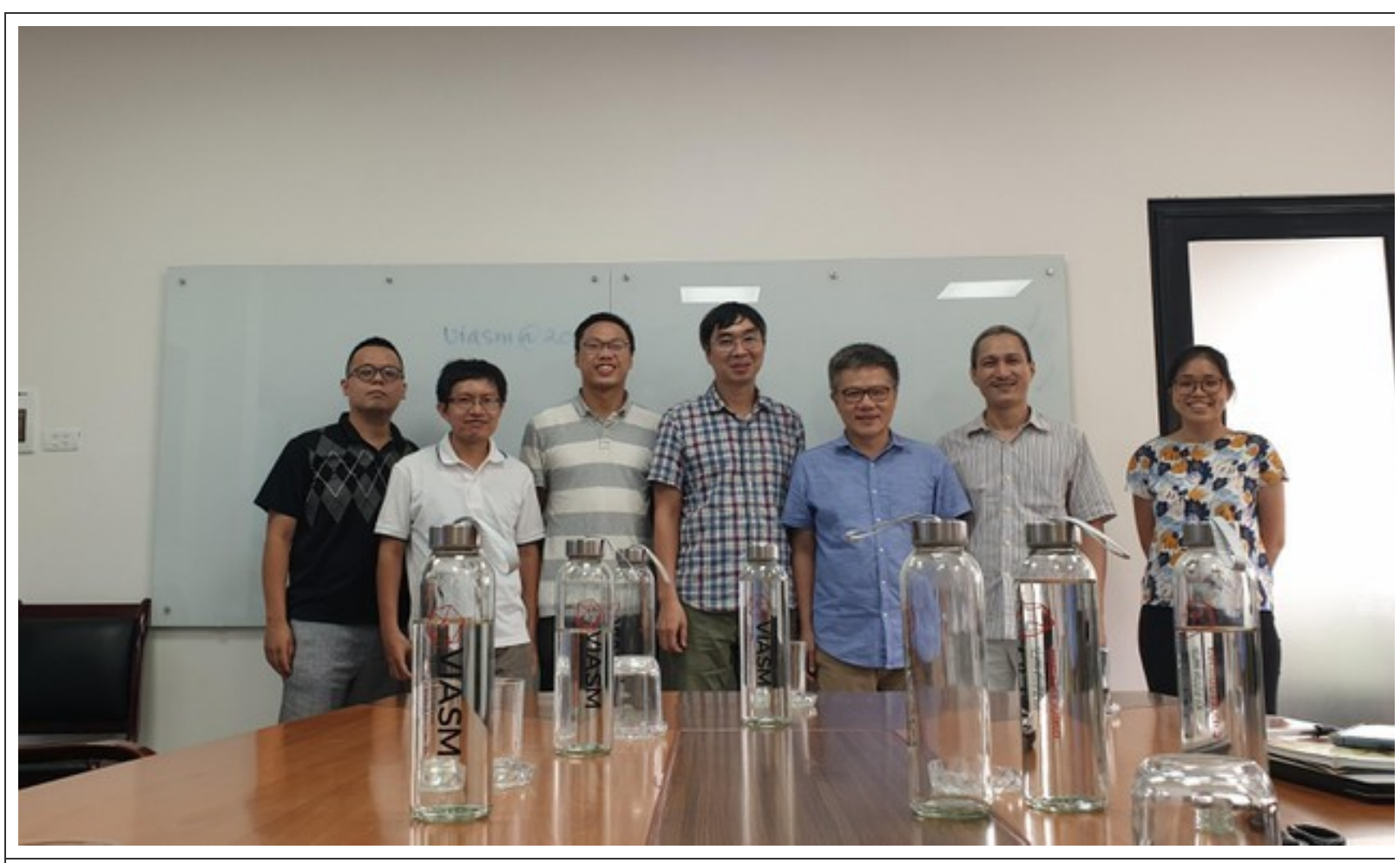

Tiến sĩ Phạm Hiệp (ngoài cùng bên trái) tham gia nhóm nghiên cứu về cơ sở dữ liệu ngành $\mathrm{t}$ Nam do Giáo sư Ngô Bảo Châu và Tiến sĩ Vương Quân Hoàng chủ trì (ảnh: NVCC)

Khi phóng viên đặt vấn đề, đầu tư cho nghiên cứu khoa học trong nhiều trường hợp là đầu tư rủi ro, đầu tư mạo hiểm thì vị này cho rằng: "Đã đầu tư cho khoa học thì phải chấp nhận vấn đề rủi ro và mạo hiểm vì khi làm nghiên cứu không ai dám chắc có kết quả đầu ra hay không”. 
Do đó cần có biện pháp thúc đẩy để sao cho nâng cao hiệu quả và giảm đầu tư nhầm chỗ, lãng phí. Để làm được điều này thì về mặt quản lý nhà nước cẩn hệ thống cơ sở dữ liệu khoa học để đánh giá chất lượng, năng suất từ cấp vĩ mô (chương trình khoa học công nghệ cấp quốc gia) đến đánh giá từng trường, viện nghiên cứu cho đến từng cá nhân.

Giám đốc nghiên cứu, Trung tâm Nghiên cứu và Phát triển giáo dục Edlab Asia khẳng định: "Khi có hệ thống đánh giá đủ tốt thì sẽ kiểm soát được kết quả nghiên cứu và năng lực nghiên cứu của từng chương trình, từng đơn vị, từng cá nhân.

Sau đó chúng ta có chính sách đầu tư cho khoa học dựa theo kết quả. Nhờ vậy sẽ kích thích được vấn đề chất lượng hiệu quả, giảm lãng phí”.

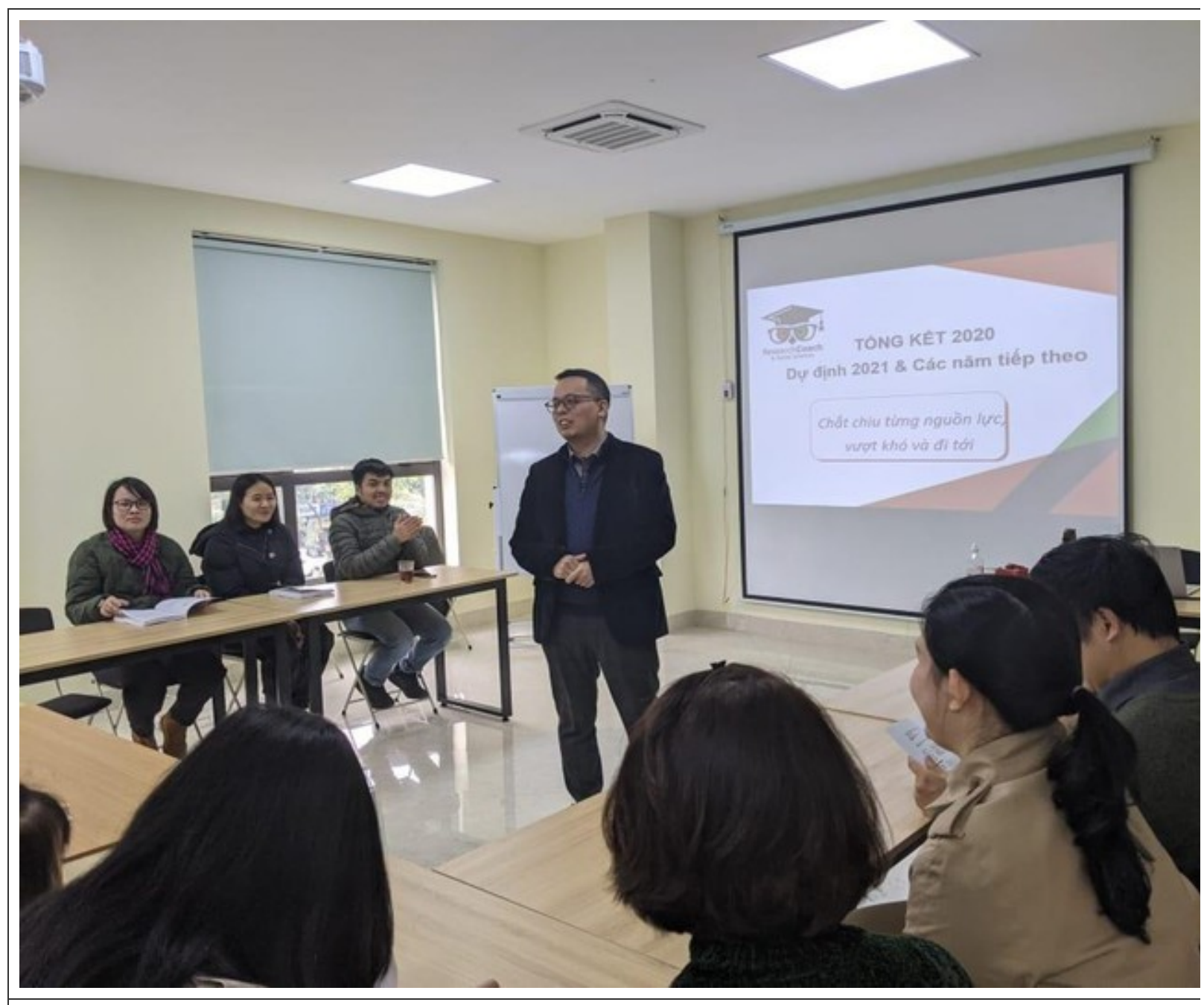

Nhóm nghiên cứu của Tiến sĩ Phạm Hiệp (đứng giữa) họp tổng kết năm 2020 (ảnh: NVCC)

Đánh giá về mức độ quan tâm và những chính sách đầu tư cho nhóm nghiên cứu của các cơ quan quản lý cấp Bộ, ngành trong thời gian qua, Tiến sĩ Phạm Hiệp nhận thấy Chính phủ và 2 Bộ Khoa học và Công nghệ; Bộ Giáo dục và Đào tạo đang có dự thảo thông tư, nghị định cho nhóm nghiên cứu, đây là tín hiệu rất tốt, hi vọng sớm đi vào thực tiễn.

Ngược lại, từ phía cơ sở giáo dục đại học, rất nhiều trường đã chủ động tổ chức nhóm nghiên cứu theo nhiều mô hình, cơ chế hoạt động khác nhau.

"Dần dần nhóm nghiên cứu sẽ trở thành thiết chế không thể thiếu ở trong mỗi trường đại học; đồng thời chứng minh hiệu quả của nó so với các thiết chế khác như 
là thiết chế bộ môn, trung tâm nghiên cứu.

Rõ ràng, kết quả nghiên cứu khoa học của Việt Nam trong những năm gần đây không thể nào không nhắc tới vai trò của mô hình của nhóm nghiên cứu", Tiến sĩ Phạm Hiệp khẳng định.

Tuy nhiên, ông cũng cho rằng thời gian tới còn nhiều việc phải làm để có thể thực sự khai thác hết tiềm năng của nhóm nghiên cứu.

Đó là, các nghiên cứu đỉnh cao và những nghiên cứu có tính thực tiễn cao thì xu hướng thế giới là cần có sự kết hợp liên ngành. Trong khi các trường đại học của ta không phải trường nào cũng là liên ngành. Do đó, tới đây, nhà nước và các trường đại học cần ban hành chính sách thúc đẩy các nhóm nghiên cứu có sự hợp tác liên ngành, liên lĩnh vực, liên đơn vị.

Đồng thời cần phải có sự kết hợ giữa đào tạo sau đại học với nghiên cứu khoa học, vì các nhóm nghiên cứu của chúng ta trừ một vài trường hợp hãn hữu ở một số đại học đa ngành đa lĩnh vực như 2 đại học quốc gia, Trường Đại học Bách khoa Hà Nội...có sự tham gia của giáo sư, phó giáo sư, giảng viên, nghiên cứu sinh, học viên cao học nhưng rất nhiều nhóm nghiên cứu hiện nay đâu đó vắng bóng nghiển cứu sinh, học viên cao học.

Vì chương trình đào tạo tiến sĩ, thạc sĩ của ta hoặc chưa thu hút được học viên giỏi hoặc chưa tạo được cơ chế để học viên dành 100\% ở các nhóm nghiên cứu, phòng thí nghiệm để làm việc với các giáo sư, phó giáo sư.

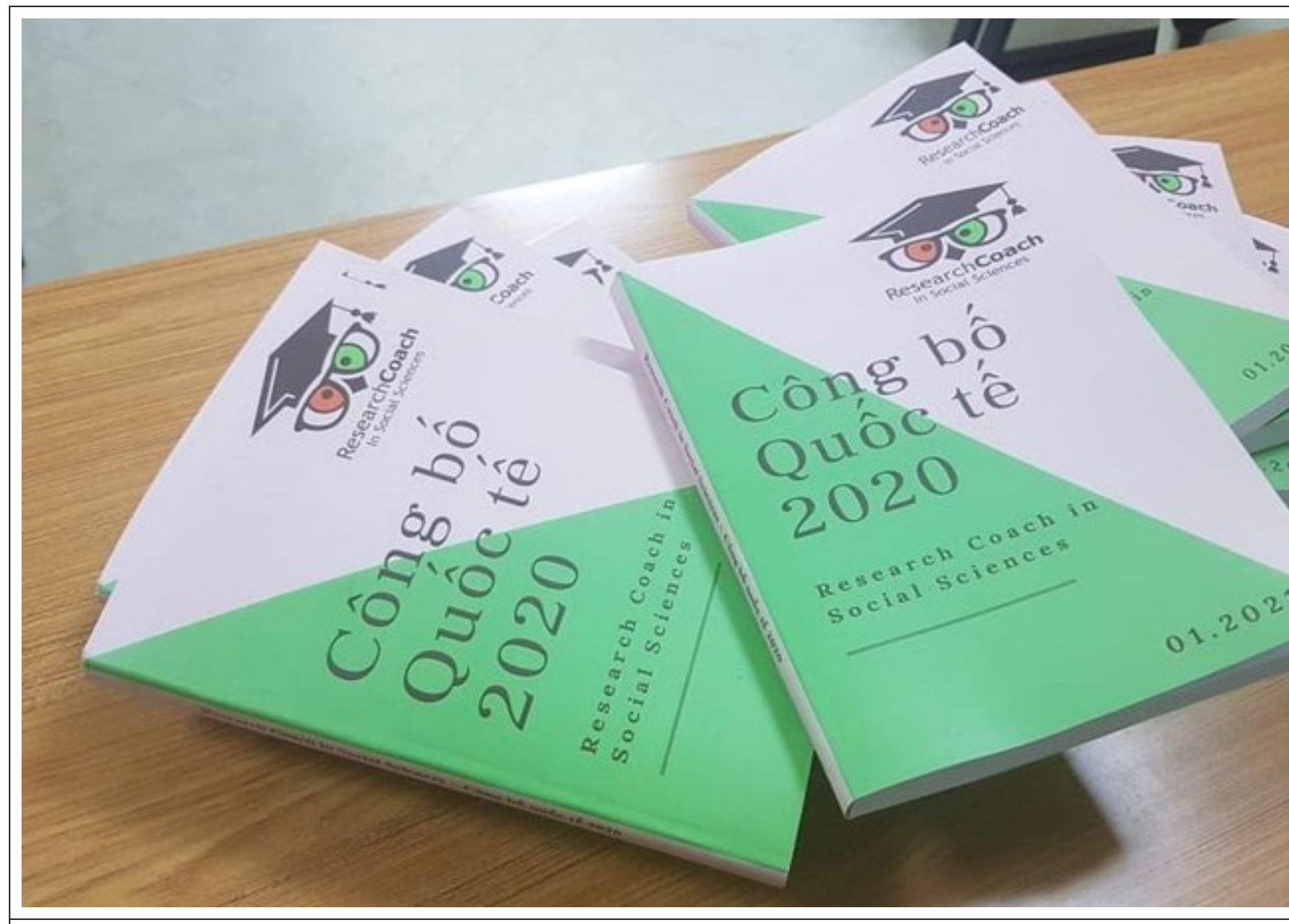

Ân phẩm tổng kết các công bố quốc tế do Tiến sĩ Phạm Hiệp làm trưởng nhóm tại Trung tâm cứu và Phát triển Giáo dục EdLab Asia. Năm 2020, nhóm của Tiến sĩ Hiệp đã cổng bố 20 bà các tạp chí ISI/Scopus (ảnh: NVCC)

Ngoài ra, theo Tiến sĩ Phạm Hiệp, để có những nhóm nghiên cứu mũi nhọn, nhóm 
nghiên cứu đỉnh cao có thể cạnh tranh được với khu vực và thế giới thì cần phải có cơ chế.

Đặc biệt, chúng ta đã có những nhà khoa học nằm trong tốp thế giới, nhiều nhà khoa học tọt vào tốp 100.00o nhà khoa học có trích dẫn nhiều nhất thế giới...

“Theo tôi, những nhà khoa học được giải thưởng nhiều thì cần phải có cơ chế và tạo đầu tư mạnh mẽ hơn những nhà khoa học đầu ngành, đầu đàn để thực sự giúp họ phát huy hết tiềm năng.

Hoặc những ngành, lĩnh vực mà Chính phủ ưu tiên tùy do Chính phủ hoặc Bộ Khoa học và Công nghệ xác định ví dụ ưu tiên công nghệ sinh học, công nghệ vật liệu, chuyển đổi số, đổi mới sáng tạo ....thì cần có đầu tư riêng cho lĩnh vực được coi là ưu tiên đó”, chuyên gia này nói.

Những dữ liệu mà chúng ta có cho thấy sự phát triển khoa học công nghệ của Việt Nam trong những năm vừa qua đóng vai trò ngày càng quan trọng và vai trò chủ yếu là từ các cơ sở giáo dục đại học.

Bước sang năm mới 2021, Tiến sĩ Phạm Hiệp kỳ vọng khoa học công nghgệ Việt Nam tiếp tục phát triển ở các trường đại học và thực sự trở thành hoạt động không thể thiếu của trường đại học.

\section{Thùy Linh}




\section{Tài liệu tham khảo:}

[1] VIASM. (2020). Lễ ký kết thỏa thuận hợp tác giữa Viện Nghiên cứu cao cấp về Toán và Quỹ Đổi mới Sáng tạo Phenikaa. Viện Nghiên cứu cao cấp về Toán (Jan. 2). http://viasm.edu.vn/hoat-dong-khoa-hoc/tin-tuc/chi-tiet/le-ky-ket-viasm-vaphenikaa

[2] Chau, N. B., Hoang, V. Q., Phuong, L. V., Hoa, L. T., et al. (2020). The 80-year development of Vietnam mathematical research: Preliminary insights from the SciMath database on mathematicians, their works and their networks. arXiv preprint; arXiv:2011.09328. 